University of the Pacific

Scholarly Commons

$4-1-2016$

\title{
Educational Outcomes of Small-Group Discussion Versus Traditional Lecture Format in Dental Students' Learning and Skills Acquisition.
}

Ana Arias

Raymond Scott

Ove A. Peters

University of the Pacific, opeters@pacific.edu

Elizabeth McClain

Alan H. Gluskin

Follow this and additional works at: https://scholarlycommons.pacific.edu/dugoni-facarticles

Part of the Dentistry Commons

\section{Recommended Citation}

Arias, A., Scott, R., Peters, O. A., McClain, E., \& Gluskin, A. H. (2016). Educational Outcomes of Small-Group Discussion Versus Traditional Lecture Format in Dental Students' Learning and Skills Acquisition.. Journal of Dental Education, 80(4), 459-465.

https://scholarlycommons.pacific.edu/dugoni-facarticles/358

This Article is brought to you for free and open access by the All Faculty Scholarship at Scholarly Commons. It has been accepted for inclusion in All Dugoni School of Dentistry Faculty Articles by an authorized administrator of Scholarly Commons. For more information, please contact mgibney@pacific.edu. 


\title{
Educational Outcomes of Small-Group Discussion Versus Traditional Lecture
}

\section{Format in Dental Students' Learning and Skills Acquisition}

\author{
Ana Arias, PhD; Raymond Scott, DDS; Ove A. Peters, PhD; Elizabeth McClain, PhD; \\ Alan H. Gluskin, DDS
}

Abstract: The aim of this prospective quantitative study was to compare the effect of different instructional formats on dental students' skills and knowledge acquisition for access cavity preparation. All first-year dental students were invited to participate in this study conducted during the four consecutive two-week endodontic rotation courses at the University of the Pacific Arthur A. Dugoni School of Dentistry in spring semester 2015. Four alphabetically distributed intact groups of students were randomly allocated to two groups $(\mathrm{n}=70 \mathrm{each})$ that participated in either small-group discussion or a traditional lecture on access preparation. The first outcome measure was skill acquisition, measured by the quality of access cavities prepared in extracted teeth at the conclusion of the session. Two blinded raters scored direct observations on a continuous scale. Knowledge, the second outcome measure, was scored with a multiple-choice and open-ended question test at the end of each two-week session. Data were obtained for 134 of the 140 students, for a $96 \%$ response rate. The results showed that students in the small-group discussion groups scored significantly higher than those in the lecture groups when skill performance was tested $\left(\mathrm{p}=8.9 \times 10^{-7}\right)$. However, no significant differences were found in the acquisition of knowledge between the two groups on the written test. Active student participation was significantly related to improved manual skill acquisition, but the format of the session does not seem to have had a direct influence on acquired knowledge.

Dr. Arias is Professor, Department of Conservative Dentistry, School of Dentistry, Complutense University, Madrid, Spain; Dr. Scott is Associate Professor, Department of Endodontics, Arthur A. Dugoni School of Dentistry, University of the Pacific; Dr. Peters is Co-Chair, Department of Endodontics, Arthur A. Dugoni School of Dentistry, University of the Pacific; Dr. McClain is Associate Dean of Academic Affairs and Associate Professor, Medical Education Department, College of Osteopathic Medicine, William Carey University; and Dr. Gluskin is Co-Chair, Department of Endodontics, Arthur A. Dugoni School of Dentistry, University of the Pacific. Direct correspondence to Dr. Ana Arias, Arthur A. Dugoni School of Dentistry, University of the Pacific, 155 Fifth Street, San Francisco, CA 94103; 415-926-2023; aa@ana-arias.com.

Keywords: dental education, educational methodology, preclinical skills, small-group format, endodontics

Submitted for publication 7/10/15; accepted 10/1/15

$\mathrm{T}$ Traditional pedagogy is based on large lecture classes as the method to transmit information from teacher to student. ${ }^{1}$ This approach assumes that the lecture format allows for presentation of the largest amount of information in the shortest period of time with the most efficient use of faculty time. Though delivery of a single lecture to a large group of students is cost-effective, this pedagogical method is often ineffective because students' attention in passive listening settings is difficult to maintain for durations longer than ten minutes. ${ }^{2}$

Educators have recommended new teaching formats based on a small-group structure. These formats offer the opportunity for active student participation and make students partners in the educational process. Incorporating these educational approaches may encourage the development of student learning characteristics, such as critical thinking, self- directed learning, and problem-solving by fostering interdependent learning as opposed to independent learning. ${ }^{1}$ Unfortunately, a recent systematic review reported the body of evidence available to guide medical educators on how to teach to students is small, albeit of good quality. ${ }^{3}$ Teaching and learning are very complex phenomena. However, educational planning must take into consideration students' preferences and diversity of learning styles along with such practical factors as number of students, human resources available, and material resources of the institution. Educational methods in health care professions must also emphasize learning skills and competence rather than judging them on the provision of information alone. ${ }^{1}$

One study reported that students preferred to work in teams. ${ }^{4}$ In fact, when compared to traditional lectures, small-group discussion methods have been 
found to promote communication, problem-solving, and interpersonal skills, ${ }^{4}$ prepare students for teamwork, ${ }^{5}$ provide more time for change of thought and deeper understanding of problems, ${ }^{6}$ and create a more motivational environment. ${ }^{7}$ Another study found a higher level of enjoyment and sense of educational stimulation $^{8}$ and engagement with the content. However, greater educational value was perceived in lecture formats in a randomized controlled study. ${ }^{9}$ Netterstrøm et al. found that some students preferred listening to teachers who knew the material and did not think it possible for them to take responsibility for their learning. ${ }^{10}$ According to Jackson et al., other challenges when students worked in small groups included the influence of cultural or motivational differences, personality of participants, and logistical issues. ${ }^{11}$

When instructors have been interviewed about their impressions after using collaborative learning approaches, the studies identified positive aspects. These included a sense of camaraderie and cohesiveness in the classroom, as well as a greater opportunity for instructors to interact with individual students. ${ }^{12}$ Another study found that teachers were surprised when some students reported negative attitudes to a collaborative learning environment and had to change the teaching style back to more traditional approaches. ${ }^{10}$

However, the evidence is mixed linking specific teaching techniques to improved knowledge outcomes and skill acquisition. When students in de Villiers et al.'s study reflected on their impressions of small-group learning, they reported a feeling of improvement in both knowledge and clinical skills. ${ }^{6}$ Likewise, Bahar-Özvaris et al. found students in small-group teaching formats gained more knowledge between pre- and posttests than students in a control group, ${ }^{13}$ and Ferreri and O'Connor reported small-group students' improvement as measured by grades at the end of the year. ${ }^{4}$ By contrast, Fischer et al. and Haidet et al. reported no improvement in students' test scores after a change in the delivery format of the class. ${ }^{8,9}$

As a result, there is a lack of consensus on the benefits of small-group methods for knowledge outcomes. At the same time, educators in the health care professions are challenged to introduce effective and efficient educational methods to increase students' acquisition of the requisite knowledge and skills. These factors and the demands on faculty time point to the need for additional data on the impact of new teaching formats compared to traditional methods.
The aim of this prospective quantitative study was to compare the effect of two instructional formats (small-group discussion and traditional lecture) on first-year dental students' knowledge and skills in pulpal access cavity preparation for endodontic therapy.

\section{Materials and Methods}

After the Institutional Review Boards of the University of the Pacific (IRB proposal \#15-71) and the University of New England (IRB022015-012) determined the study to be exempt, first-year DDS students at the University of the Pacific Arthur A. Dugoni School of Dentistry were given information about the study, invited to participate, and asked to sign an informed consent. All 140 first-year students (Class of 2017) were invited to participate in this prospective quasi-experimental study. At the beginning of the 2014 academic year, students were equally distributed into four groups using non-random, alphabetical categorization for all preclinical instruction. The four groups of 35 students each were then randomly allocated to one of two formats: traditional lecture or small-group discussion ( $\mathrm{n}=70$ in each).

The study was conducted in the four consecutive two-week endodontic rotation courses. The twoweek course was given to each group in succession over eight weeks. This course traditionally consisted of standard lectures followed by hands-on exercises. Knowledge and skills necessary to accomplish a correct access cavity preparation for endodontic therapy are different than for the rest of the endodontic procedure and can be assessed independently. ${ }^{14}$ As this topic is taught in the third educational session of the two-week rotation, it was selected as appropriate for the study.

The traditional lecture format was used for the control group. In the experimental group, the lecture was replaced by a small-group discussion. A randomized, two-group research design was used to test the effectiveness of these instructional formats on skills and knowledge acquisition for access cavity preparation. The independent variables were the two teaching formats. The dependent variables were skills and knowledge acquisition for access cavity preparation.

In the control group, a single instructor delivered a 90-minute traditional lecture on access cavity preparation for various groups of teeth; the lecture also incorporated videos showing the procedure. For 
the experimental group, the 35 students in each block were distributed into three working groups with 11 to 12 students in each group (Figure 1). Each group had a 90-minute session with a facilitator. The three groups in each rotation had the sessions at the same scheduled time. Three facilitators were used to maintain the pace of the block. The single instructor in the control group was also one of the facilitators. A calibration method was used to ensure comparable teaching experiences of all facilitators. Prior to the session, the three facilitators were provided with evidence-based guidelines on small-group facilitation.

The facilitation session was divided into two components with each lasting 45 minutes for total session duration of 90 minutes. During the first 45 minutes of the facilitation session, students were randomly distributed into subgroups of two or three students each, and a tooth type (incisors, premolars, maxillary molars, or mandibular molars) was randomly assigned to each. The departmental endodontic manual, laptops with Internet connectivity, and textbooks were available as resources for all participants. A flash-drive given to each subgroup at the beginning of the session contained images of the corresponding tooth type, two articles, and a PDF of a textbook chapter on access openings. Each subgroup also received a script explaining all the steps of the session (Table 1). Each subgroup was asked to discuss the relationship between the internal pulpal and external tooth anatomy, the ideal access outline form, frequent mishaps, and special considerations during access preparation for the assigned tooth. Students were asked to find an interesting video from the online sources that showed the correct access cavity preparation for the assigned tooth. They were told to modify the PowerPoint templates if required to further the understanding of their classmates. During the second part of the session, students in each subgroup taught the other three student subgroups what knowledge they had acquired during the first part of the session for their group's assigned tooth. All the students were required to actively participate during the second 45-minute portion of the session.

All student performance data remained confidential during the collection period. Data were kept in a secure database in a password-protected computer. Once all data were collected, individual student identification information including name and student ID was replaced with a numeric code in order to ensure confidentiality of all study participants.

Data were collected to assess acquisition of knowledge and skills. For knowledge, at the end of

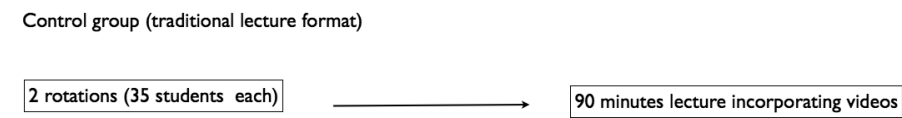

Experimental group (small group discussion format)

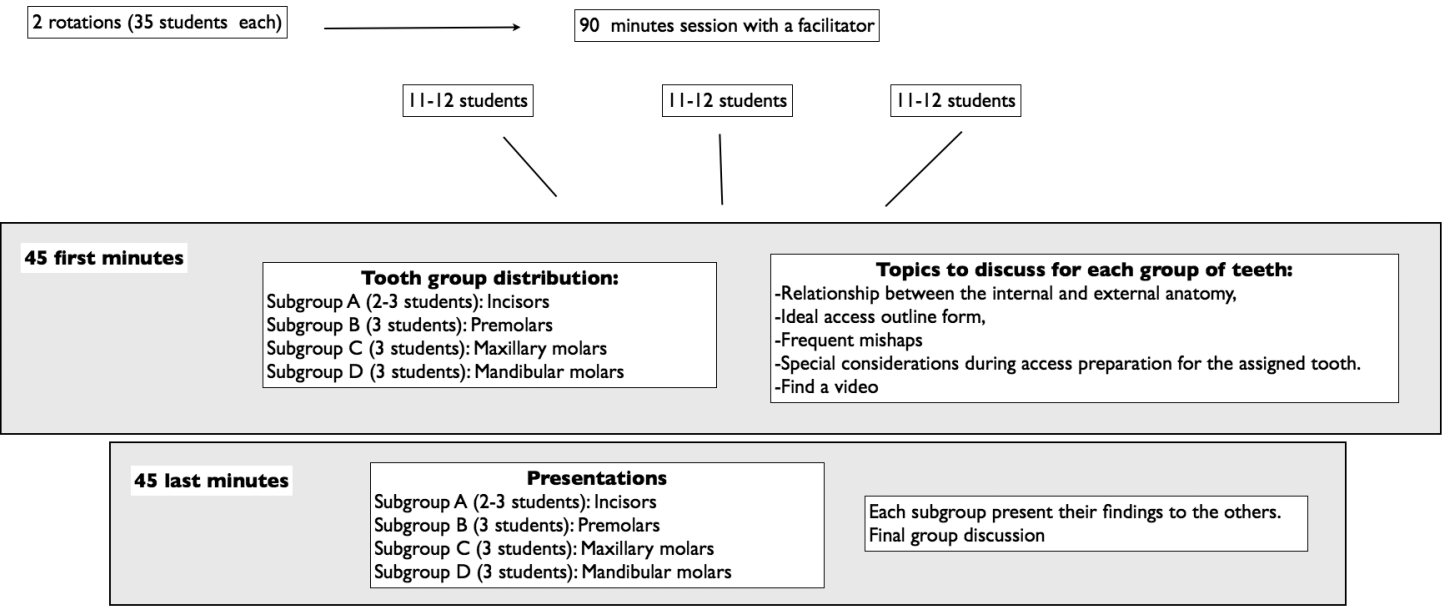

Figure 1. Design of the control and experimental groups and content of sessions 
Table 1. Script used with students in the facilitation session

Script

You must discuss in your subgroup and then present to the other subgroups the following information for the tooth types you were assigned:

A. Relationship between the pulp chamber and root canal system with the coronal and lateral external surfaces. Expected number and location of the root canals.

B. Ideal access outline form.

C. Special considerations for the type of teeth (example: long access of the root, angulation of the bur, unroofing of the pulp chamber, angulation of crown versus root).

D. Frequent mishaps and errors for the selected type of teeth.

E. Find an interesting video on the Internet for one of the tooth types assigned.

On the flash-drive given to your subgroup, there is a presentation with images that you can use to explain concepts to the other groups. You can also show them the video that you found. The presentation should not take more than 10 minutes.

The first 45 minutes of the session will be used for discussion among the members of your subgroup and preparation of the material you will present to the other subgroups. In the second part of the session (last 45 minutes), each subgroup will present its findings.

each rotation, students completed a test consisting of multiple-choice and short open-ended questions on access cavity preparations. A rater blindly scored all the written tests. For skills, at the conclusion of the learning session, students were asked to perform access cavity preparations in all the tooth types in extracted teeth. Two expert raters, through direct observation, evaluated the performance of each preparation with a grading rubric (Table 2). To prevent any undue bias, raters were blinded from each other and to both the student and the intervention group. Three parameters were scored: outline form, outline preparation, and final access. The average score of the three parameters was calculated for each tooth. Average scores of the four teeth were also calculated.

SPSS-22 (IBM Corp., Armonk, NY, USA) was used for statistical analysis. Results are reported in aggregate form to maintain confidentiality. Descriptive data investigating frequency for gender per group were calculated. Interrater reliability of average performance scores was calculated with an interclass correlation coefficient for both consistency and absolute agreement.

Data for students' average ratings of their performance in the access cavity preparations were found to be compatible with a normal distribution, and standard deviation of subgroups were similar; thus, the data were analyzed with Student's t-test. Data for Student's t-test scores in the multiple-choice examination violated the assumption of normal distribution and were analyzed with a Mann-Whitney U test. Scores of students in the three facilitation groups were compared with a Kruskal-Wallis test.

\section{Results}

Data were obtained for 134 (96\%) of the 140 students who signed the informed consent and voluntarily agreed to participate in the study. Six students did not deliver the informed consent and were excluded. Of the participating students, 68 (51.3\% females and $48.7 \%$ males) were taught in the lecture group (control group), while 66 (46.8\% females and $53.2 \%$ males) participated in the small-group discussions (experimental group).

Interrater reliability was high for both consistency $(\mathrm{ICC}=0.854 ; 95 \%$ confidence interval $(\mathrm{CI})$ $0.801-0.894)$ and absolute agreement (ICC $=0.852$; 95\% CI 0.798-0.887). No statistical differences were found in the acquisition of knowledge $(\mathrm{p}=0.25)$ between the control group (mean score $=4.30 \pm 1.2$ )

\section{Table 2. Grading rubric for access cavity preparation assessment}

$$
\text { Poor (4-5) }
$$

Outline form

Outline preparation

Access accomplished
Outline poorly executed

Excessive structure cut

Access poorly accomplished
Minor outline errors

Chamber penetration off axis

Slight irregularities in the access
Correct outline cut in dentin

Chamber opened on long axis Straight line access complete 
and experimental group (mean score $=4.49 \pm 1.11$ ). However, students in the experimental group scored significantly higher (mean score $=7.29 \pm 1.03$ ) than those in the lecture group (mean score $=6.24 \pm 1.30$ ) when skill performance was tested $\left(p=8.9 \times 10^{-7}\right)$. No significant differences were found among the scores of students in the three experimental groups.

\section{Discussion}

This study compared quantitative information on both cognitive and psychomotor outcomes for a cohort of first-year dental students randomly divided into small-group discussion and lecture format sessions. This comparison of knowledge acquisition and skills provides insight into the role of different teaching methods in students' preclinical performance. All students were invited to participate in the study, but they had no choice over the specific method of instruction they would receive. If a student declined to participate, data were not included. At the same time, attendance in the traditional lecture was offered to those students assigned to the small-group discussion format if either the student or instructor identified a concern with a cognitive or skills deficit. Neither the students nor the instructors requested or identified the need for a further traditional lecture session during the course of the study.

Small-group discussion formats are intended to foster independent thinking and problem-solving skills. Prior research has demonstrated greater satisfaction levels when students participated actively in the learning process. ${ }^{4-8}$ However, there is no consensus on the advantages in cognitive outcomes; and in some of those studies, students' group assignment was made on a voluntary basis so the outcomes may have been biased by students' preferences. In our study, intact groups were randomly allocated to either a small-group discussion or a traditional lecture session, which avoided this potential bias. A control group with the classic delivery method was used to allow the deep analysis of the effect of small-group peer learning in the integration of knowledge on preclinical performance outcomes.

Jacques described a variety of methods for successful small-group facilitation sessions. ${ }^{15}$ In our study, we followed guidelines for successful implementation of small-group discussions ${ }^{16,17}$ and gave the facilitators specific instructions on smallgroup facilitation prior to the study. The translation of Dale's Cone of Experience ${ }^{18}$ to the National Learning
Laboratories' Pyramid of Learning is controversial. The Pyramid of Learning cites up to a $90 \%$ average retention rate when teaching others and 50\% in group discussion compared to the $5 \%, 10 \%$, and $20 \%$, respectively, for the passive teaching methods of lecture, audiovisual, and demonstration. ${ }^{19,20}$ Our research team decided that the best small-group discussion method to foster active learning would be a participatory teaching method that included both group discussion and active peer teaching. In a recent review, Masters states that although there is no agreement on the percentages of learning retention reported in the Pyramid of Learning, there is still a general pattern. ${ }^{21}$

A special effort was made to design reliable and valid measures for a fair comparison of both knowledge and skills acquisition between the two teaching methods. This was important regarding students' learning strategies since outcomes are influenced not only by instructional design but also by methods of assessment. For cognitive outcomes, a test containing a representative sample of items to test important information with the appropriate level of difficulty was designed. Care was taken to avoid construct-irrelevant easiness and constructirrelevant difficulty. ${ }^{22}$ Items were obtained from a well-respected textbook in endodontics ${ }^{14}$ and edited by three content experts using principles of effective question writing. For assessing skills, the major concern was interrater reliability and consistency. It was decided that two raters would code the access cavity preparation independently using the same grading rubric used in the Department of Endodontics to grade access cavity preparations performed by senior students on patients. The grading rubric addressed all the critical aspects related to access cavity preparation for root canal therapy. In addition, both raters had been trained in use of this grading rubric and had used it extensively in the clinic over the last two years. As a result the interrater reliability was high for both consistency and absolute agreement in this study. To further avoid bias, each assessment was assigned a random number, and both raters were blinded to both the student and the learning intervention..$^{23,24}$

In this study, the format of the session seemed not to have a direct influence on the acquired knowledge at the end of the rotation; however, active student participation was significantly related to a higher skill acquisition. An improvement in preclinical endodontic skills has been previously reported when blended learning (online lectures and videos) was compared with traditional lecture formats, and 
no differences were observed in knowledge tests between the two groups. ${ }^{25}$

The significantly better performance in preclinical skills we found supports the use of small-group discussion methods in dental education. The goal of this study was not to collect students' impressions, but students in the experimental group enjoyed their active participation and thanked the facilitators for the change in the delivery format. Positive feedback was also received from the three facilitators. They reported great satisfaction after realizing that the students were more capable, knowledgeable, and insightful than they had expected. The most noticeable reaction occurred after the first experimental session. The facilitator (who was also the instructor in the lecture format and had being delivering that lecture for the last 20 years) reported that this new pedagogy was a highly rewarding and stimulating teaching experience. Other facilitators agreed that the experience was rewarding and that the students left well informed on the subject covered.

The only controversial aspect for the facilitators was the use of online resources. In spite of having textbooks physically present in the room, most students used only their laptops for research. While one of the facilitators reported his satisfaction with the great deal of information on the Internet applicable to the subject covered, another expressed his concern about first-year students' inability to critically assess what is published online and the influence this interaction may have on their knowledge acquisition. Considering a lack of control over the information available online, this concern alerts all educators to the need for curricula designed to foster critical thinking and provide sufficient understanding for the critical evaluation of research and publications found on the Internet and its integration for evidence-based practices. ${ }^{26-28}$ This is especially important in dental education during the early years because students are highly vulnerable to the information found online at a time when they are establishing their foundational knowledge base.

One limitation in this study is that it included only a particular step in a root canal treatment in an attempt to isolate the effect of the teaching methods. Further research is needed to determine if other small-group discussion formats may benefit dental students' skill acquisition. It would also be interesting to follow both groups of students during their clinical years to observe if they show any difference in skills when performing access cavity preparations with patients.

\section{Conclusion}

Within the limitations of this study, the studentdirected teaching format with a faculty facilitator did not have a direct influence on didactic knowledge acquisition for these first-year dental students. However, the format was significantly related to a higher skill acquisition. Considering the implications of dental training with patient care, these findings are relevant for health care professions in which educational methods should emphasize active learning skills and competence rather than the development of didactic knowledge alone.

\section{Acknowledgments}

This study was conducted, in part, to fulfill Dr. Arias's Master's of Science in Medical Education Leadership requirements at the University of New England. The authors wish to thank Meixun (Sinky) Zheng, $\mathrm{PhD}$, for providing the evidence-based guidelines for small-group facilitation.

\section{Disclosure}

The authors declared they have no conflicts of interest.

\section{REFERENCES}

1. Plasschaert AJM, Manogue M, Lindh C, et al. Curriculum content, structure, and ECTS for European dental schools. Part II: methods of learning and teaching, assessment procedures, and performance criteria. Eur J Dent Educ 2007;11(3):125-36.

2. Davis BG. Tools for teaching. New York: John Wiley \& Sons, 2009

3. Ilic D, Maloney S. Methods of teaching medical trainees evidence-based medicine: a systematic review. Med Educ 2014;48(2):124-35.

4. Ferreri SP, O'Connor SK. Redesign of a large lecture course into a small-group learning course. Am J Pharm Educ 2013;77(1):13.

5. Pigeon Y. Medical student learning groups. Acad Med 2001;76(5):503.

6. de Villiers M, Bresick G, Mash B. The value of smallgroup learning: an evaluation of an innovative CPD program for primary care medical practitioners. Med Educ 2003;37(9):815-21.

7. Willis SC, Jones A, Bundy C, et al. Small-group work and assessment in a PBL curriculum: a qualitative and quantitative evaluation of student perceptions of the process of working in small groups and its assessment. Med Teach 2002;24(5):495-501.

8. Fischer RL, Jacobs SL, Herbert WNP. Small-group discussion versus lecture format for third-year students in obstetrics and gynecology. Obstet Gynecol 2004;104(2):349-53. 
9. Haidet P, Morgan RO, O'Malley K, et al. A controlled trial of active versus passive learning strategies in a large group setting. Adv Health Sci Educ Theory Pract 2004;9(1): 15-27.

10. Netterstrøm I, Fiehn NE, Larsen T. Changing the curriculum and the role of the teacher and the students in the classroom: an analysis of the process of reforming a course in oral microbiology. Eur J Dent Educ 2011;15(1):26-30.

11. Jackson D, Hickman LD, Power T, et al. Small-group learning: graduate health students' views of challenges and benefits. Contemp Nurse 2014;48(1):117-28.

12. Gaudet AD, Ramer LM, Nakonechny J, et al. Smallgroup learning in an upper-level university biology class enhances academic performance and student attitudes toward group work. PLoS One 2010;5(12):e15821.

13. Bahar-Özvaris SE, Çetin FÇ, Turan S, Peters AS. Cooperative learning: a new application of problem-based learning in mental health training. Med Teach 2006;28(6):553-7.

14. Hargreaves KM, Cohen S, Berman LH. Cohen's pathways of the pulp. St. Louis: Mosby, 2011.

15. Jaques D. ABC of learning and teaching in medicine: teaching small groups. BMJ 2003;326(7387):492.

16. Azer SA. Challenges facing PBL tutors: 12 tips for successful group facilitation. Med Teach 2005;27(8):676-81.

17. Steinert Y. Twelve tips for effective small-group teaching in the health professions. Med Teach 1996;18(3):203-7.

18. Dale E. Audiovisual methods in teaching. $3^{\text {rd }}$ ed. Oak Brook, IL: Dryden Press, 1969.
19. Lalley J, Miller R. The learning pyramid: does it point teachers in the right direction? Educ 2007;128(1):64-79.

20. Letrud K. A rebuttal of NTL Institute's learning pyramid. Educ 2012;133(1):117-24.

21. Masters K. Edgar Dale's pyramid of learning in medical education: a literature review. Med Teach 2013;35(11):1584-93

22. Brualdi A. Traditional and modern concepts of validity. Eric/Ae Digest. Washington, DC: ERIC Clearinghouse on Assessment and Evaluation, 1999:1-4.

23. Downing SM. Reliability: on the reproducibility of assessment data. Med Educ 2004;38(9):1006-12.

24. Downing SM. Validity: on meaningful interpretation of assessment data. Med Educ 2003;37(9):830-7.

25. Maresca C, Barrero C, Duggan D, et al. Utilization of blended learning to teach preclinical endodontics. J Dent Educ 2014;78(8):1194-204.

26. Slawson DC, Shaughnessy AF. Teaching evidence-based medicine: should we be teaching information management instead? Acad Med 2005;80(7):685.

27. Miles S, Price GM, Swift L, et al. Statistics teaching in medical school: opinions of practicing doctors. BMC Med Educ 2010;10:75.

28. Pawar N. Need for intensive training on research methodology in medical education. National J Community Med 2011;2(2):179-80. 